WORKING PAPER · NO. 2020-143

\title{
Impact of the COVID-19 Crisis on Family Dynamics in Economically Vulnerable Households
}

Ariel Kalil, Susan Mayer, and Rohen Shah OCTOBER 2020 
Impact of the COVID-19 crisis on family dynamics in economically vulnerable households

\author{
Ariel Kalil \\ akalil@uchicago.edu \\ Susan Mayer \\ smayer@uchicago.edu \\ Rohen Shah \\ shahr@uchicago.edu
}

Harris School of Public Policy Studies

University of Chicago

October 2020

Acknowledgements: The COVID-19 study conducted in the spring of 2020 was funded by the Becker Friedman Institute at the University of Chicago. Funding for the original studies from which the COVID-19 sample was drawn was provided by the Valhalla Charitable Foundation, the Overdeck Family Foundation, Heising-Simons Foundation, Robert R.McCormick Foundation, and Paul M. Angell Family Foundation. Ana Arellano Jimenez and Paula Rusca provided invaluable research assistance. 


\begin{abstract}
The COVID-19 crisis and its reverberations resulted in levels of economic distress unprecedented since the 1930s. But COVID was a seismic social shock even for families that lost no income, due at least in part to abrupt school closures and the widespread threat of illness and death. The COVID-19 crisis will not affect all families equally, but may cause particular harm to children of low-income and less-educated parents and for preschool age children, who are especially sensitive to developmental inputs. We surveyed 572 low income families with preschool-age children in Chicago to understand family dynamics following the economic and social restrictions imposed by the pandemic. We separately examine the associations between economic hardship, exposure to the virus, and pandemic-induced increases in childcare time on parental mental health and stress, parent-child interaction, and children's adjustment. We find both positive and negative effects: Parental job and income losses are strongly associated with parents' depressive symptoms, stress, diminished sense of hope, and negative interactions with children. However, these ill effects do not occur for parents who lose jobs but do not experience concomitant income losses. In fact, job losses without income losses are associated with more positive parent-child interactions. Parents' exposure to COVID-19 is associated with less positive parent-child interactions and more child behavior problems. In contrast, parents who report spending substantially more time in childcare as a consequence of the pandemic report more positive parent-child interaction. We discuss the implications of these results for policy and practice.
\end{abstract}


Introduction

The coronavirus pandemic represents the biggest shock to the American economy since the Great Depression. Following the imposition of stay at home orders across the country, the U.S. labor market collapsed over roughly two weeks in late March and early April. But COVID19 was a seismic social shock even for families that lost no income, due at least in part to abrupt school closures and the widespread threat of illness and death. In many instances, the school closures substantially increased the time that parents, especially mothers, spend with their children (Baxter et al., 2020; Calarco et al., 2020; Sevilla \& Smith, 2020). For schoolchildren, school closures and learning interruptions could threaten children's learning and adjustment (Kuhfeld et al., 2020) but the effects will depend on the quantity and quality of parent-child interaction at home. Low income children may be at greater risk for learning losses and behavioral stress than high income children given average pre-pandemic differences in parent engagement in children's learning (Kalil et al., 2012).

The novel coronavirus has been more prevalent among low income families resulting in much more anxiety in these families about threats to their health and well-being. The changes arising from the novel coronavirus can also have a direct effect on the level of distress parents and children experience arising from social isolation due to stay at home orders, including physical and social distance from their friends and schools and changes to their usual daily routines. Parental and child well-being may be diminished by concerns about their own and their family's health as a consequence of exposure to the virus itself.

The COVID-19 crisis will not affect all families equally, but may cause particular harm to children of low-income and less-educated parents, who tend to have lower academic and socioemotional skills compared to higher income or more educated parents already (Attanasio et al., 
2020) and for preschool age children, who are especially sensitive to developmental inputs that shape lifelong attainment and achievement (Duncan \& Magnuson, 2011).

In this paper we compare the relative importance of pandemic-induced economic hardships (i.e job and income loss and inability to make ends meet) versus pandemic-induced social conditions (i.e., exposure to the virus and pandemic-induced increases in child care time) as they relate to parental mental health and stress, parent-child interactions, and children's behavioral adjustment.

\section{Background}

The economic and social shifts arising from COVID-19 represent key forces capable of shaping the future life courses of American children. The associations between parental economic stress, parent mental health and behavior, and children's socio-emotional adjustment in the short and long term are well documented (Del Boca et al., 2014; Fiorini \& Keane, 2014; Hsin \& Felfe, 2014; Jackson et al., 2000; Kalil \& Ryan, 2020). Existing research on the relationship between the COVID-19 pandemic and family life has largely focused on its economic and mental health impacts (Calarco et al., 2020; Gassman-Pines et al., 2020). The COVID-19 pandemic and the policy response to it - including stay-at-home orders, new regulations for essential workers, and school closures - may create a stressful environment for families through many channels: worries about health; pressures related to going to work, working from home or the potential of job loss and consequently income loss; the need to homeschool children, and other possible consequences of living through this pandemic. These stresses could diminish the quality of parent-child interactions (Kalil, 2013), which may in turn amplify socio-emotional or behavioral problems in children. 
On the other hand, the effects of the pandemic need not be uniformly negative (note, however, that we consider the potential effects of exposure to the virus itself to be uniformly negative). One unique feature of the economic policy response was the federal stimulus funds targeting lower income households and delivered to families in the late spring. Unemployment insurance was expanded in unprecedented ways during the current COVID-19 pandemic. Indeed, large numbers of families experiencing job losses actually enjoyed higher incomes during their period of unemployment as compared to the pre-pandemic time during which they were employed (Ganong et al., 2020). Thus, for some families, this period was tantamount to a paid family leave. The rapid and generous early federal response to supporting the unemployed are a unique feature of the COVID-19 pandemic, distinguishing it from prior periods of high job loss such as the Great Recession of 2008.

Parent time (especially mothers' time) in childcare has increased in the wake of school closings and stay at home orders (Baxter et al., 2020; Calarco et al., 2020; Sevilla \& Smith, 2020). The effects of an increase in time with children are uncertain. On one hand, caring for young children while isolated at home and potentially also juggling employment may be stressful for at least some mothers. However, nationally-representative data show that the time that parents spend in child care provides the most feelings of positive affect and meaning compared to the time that parents spend engaged in any other activity and that this is especially true for low-income parents (Kalil et al., 2019). Calarco and colleagues (2020) surveyed 139 mothers from a range of income levels during the spring of 2020, finding that on average mothers who have greatly increased the time they spend caring for their children during the pandemic have disproportionately experienced substantial increases in stress, anxiety, and frustrations with their children. However, this was true primarily for mothers who held themselves to a high standard of 
"intensive parenting." Other mothers in their sample did not experience increased time with their children as a substantial source of stress and indeed even characterized the increased parenting time as a source of joy in otherwise difficult times.

The drivers of family dynamics and children's adjustment in economically vulnerable families during the novel coronavirus pandemic are not yet fully understood. The present paper examines how economic and social features of the pandemic may be associated with key aspects of parental mental health and family dynamics. The family dynamics we focus on as outcomes capture three types of interactions between parents and children known to be central in the development of young children's socio-emotional adjustment and anticipated to play a role in amplifying or mitigating the response to the novel coronavirus (Landry et al., 2006; Linver et al., 2002; Moroni et al., 2019). These characteristics include parental mental health and stress, parents' time investments in children's development, and the quality of parent-child interactions. We also examine parents' reports of children's behavioral adjustment.

Parental mental health and stress: Parental mental health problems, such as loneliness, hopelessness, depressive symptoms, and parenting stress are risk factors for a more stressful home environment (Conger et al., 2002). Unfortunately, low income parents in the US are already at risk for higher levels of mental health problems even absent the pandemic (Jackson et al., 2000). To the extent that the stresses of the COVID-19 crisis worsen parental mental health and increase stress this may increase children's behavioral and socioemotional problems.

Time investments. The time that parents spend with their children on developmentally stimulating or educational activities are important determinants of childhood development (Attanasio et al., 2020; Kalil \& Ryan, 2020; Price \& Kalil, 2019). Changes in parental employment induced by the COVID-19 pandemic may have increased the time that parents have 
available to be with their children but may also have changed the organization and patterns of family life, including how parents spend their time at home and with their children.

Consequently, we do not know whether the changes in time distribution helped or hindered child development. The children in economically disadvantaged households receive less time investment even absent the pandemic (Kalil \& Ryan, 2020; Kalil et al., 2012). It is possible that unemployed parents might increase time caring for children or other types of home production in response to reduced work in the marketplace. However, parents may spend less time in home production or with their children during the pandemic, perhaps because they do not know how to productively invest the time they do have in their children or because they or a family member is sick.

Quality of parent-child interaction. Researchers have considered parenting style - such as how warm, strict, or communicative a parent is - as an important determinant of a child's skills (Doepke \& Zilibotti, 2019; Gershoff et al., 2012). During a period when schools are closed, parents may have more opportunities to spend time with children and this may produce more positive parent-child interactions. However, the disruptions caused by changes in routines and economic changes or the threat of illness may produce more negative interactions. Harsh parenting - including shouting at young children may exacerbate children's behavioral and emotional problems (Pinderhughes et al., 2000; Straus \& Stewart, 1999). Even absent the pandemic, children in low income homes experience harsh parenting more often than do children in higher-income homes (Ryan et al., 2016).

\section{Developmental Timing}

Our study focuses on families with preschool age children; early childhood is hypothesized to be a particularly sensitive period for exposure to economic and social stress. 
Both human and animal studies highlight the critical importance of early childhood for brain development and for establishing the neural functions and structures that will shape future cognitive, social, emotional and health outcomes (Sapolsky, 2004; Shonkoff \& Phillips, 2000). Research in other fields also highlights the developmental sensitivity of the early childhood period. Cunha and colleagues (2006) propose an economic model of development in which preschool cognitive and socio-emotional capacities are key ingredients for human capital acquisition during the school years. In their model, early capacities can affect the likelihood that later school- age human capital investments will be successful and productive. This model predicts that economic deprivation, such as that which may arise from job or income losses, in early childhood creates disparities in school readiness and early academic success that widen over the course of childhood. Duncan and colleagues (2010) presented evidence showing the developmental sensitivity of the early childhood period to the effects of low income on later life outcomes.

\section{Method}

\section{Survey Methodology}

We surveyed low-income parents of preschool-age children in the Chicago area about the impact of the COVID-19 pandemic. Survey data collection began May 3 and ended July 20, 2020. Participants are those who are currently or were recently participating in other research studies conducted by the Behavioral Insights and Parenting Lab at the University of Chicago. These families were originally recruited from preschools in Chicago offering subsidized care to low income families. We had telephone numbers for these families and so were able to rapidly contact them. There was a total of 1,128 parents in the two previous studies. Of these 784 still 
had valid phone numbers in spring of 2020 and of these we were able to complete surveys with 572 parents, representing a $73 \%$ response rate.

All participants received an initial text message with a unique survey code and link to complete the survey online. Participants who did not opt out by replying they were not interested in completing the survey received two more text message reminders to complete the survey. The second reminder notified participants that our team would be calling them the following week to help them complete the survey over the phone. Thirty parents refused to take the survey, and the other parents who were not surveyed either ignored our calls or continued to reschedule when we called. For participants who did not answer or schedule a follow-up call, we called an average of 10 times before assuming that the person did not want to participate. Of the 572 surveys 59\% were completed by phone, and $41 \%$ were completed online. The average duration of the phone survey was 21 minutes. The survey was approved by the Institutional Review Board at the University of Chicago.

\section{Measures}

The independent variables include job and income loss, perceived inability to make ends meet, own or householder's possible exposure to COVID-19; and pandemic-induced increase in childcare time. The dependent variables broadly fall into three categories: parental mental health, parent-child interaction, and children's adjustment. Each of these variables is described in detail below.

Job and Income Loss. Participants were asked both about changes in employment and income as a consequence of the pandemic. The question on job loss asked "How has your employment changed due to the current crisis?" The response options included: "I lost my job and am now unemployed," "I lost my job and am now in a different job," "I did not lose my 
job," "I was not working before and am now in a new job" and "I was not working before and am still not working." We consider it a "job loss" if the participants chose "I lost my job and am now unemployed." This measure thus captures job losses and unemployment that the participants attribute to the pandemic.

The question on income loss is: "How has your total household income changed since the start of the current crisis?" The response options were "It has gone down a lot," "It has gone down a little," "It has stayed about the same," "It has gone up a little," and "It has gone up a lot." We consider a participant as having "income loss" if they reported that their income "has gone down a lot."

We then split the participants into four mutually exclusive groups: those with both job and income loss, those with only job loss, those with only income loss, and those with neither job nor income loss. In order to represent this categorical variable in a regression, we created 3 dummy variables: "Job and income loss (15\% of the sample)," "Only job loss $(9 \%$ of the sample)," and "Only Income Loss (21\% of the sample)."

It is important to underscore that job loss is at the individual level whereas household income loss is at the household level. This is how it is possible for a parent to report that he or she did not lose his or her job but the household income nonetheless declined due to another householder's job loss. Or the parent might not have lost his or her job but work hours may have declined, leading to an income loss. Conversely, as we noted previously, the unique feature of the pandemic is that public policy intervention meant that those who experienced job loss did not necessarily also experience an income decline. For these reasons it is important to distinguish job and income losses that occur jointly in the COVID-19 pandemic from those in which families experience only one of these events.. 
Struggle to Make Ends Meet. Participants were asked "Think about (last month): Which of these best describes how much money you will have left over at the end of (that month)? The response options included "Some money left over," "Just enough money to make ends meet," and "Not enough money to make ends meet." We create a "struggle to make ends meet" dummy variable, where those who replied "not enough money to make ends meet" were assigned a value of 1 , and those who said just enough to make ends meet or some money left over were given a 0 . Twenty percent of the sample struggled to make ends meet.

COVID Exposure. This is a dummy variable with a value of 1 if participants said they or someone in their household was sick with symptoms of COVID and a 0 otherwise. $10 \%$ of participants reported COVID exposure.

More Time on Childcare. This is a dummy variable with a value of 1 if participants said they spend a "lot more time" taking care of household children since school closings, and a 0 if they said "a little more," "same," or "less time." 74\% of participants in the sample reported spending a lot more time on childcare.

Depressive Symptoms Scale. Participants were asked two questions relating to depressive symptoms they might have experienced in the past two weeks: one on "how often have you had little pleasure in doing things?" and another on "how often have you felt down, depressed or hopeless." Participants were first assigned 0 for "Not at all," 1 for "Several days," 2 for "More than half the days," and 3 for "Nearly every day" for each of two questions. The depressive symptoms score is the sum of these values across both questions, thus ranging from 0 to 6 . The average score on the scale was 0.99 , indicating a relatively low level of depressive symptoms. 
Life Stress. Participants were asked "How stressful do you find your life right now?" and were asked to choose a number between 0 and 10, where 0 means not at all stressful and 10 means extremely stressful. The average life stress score in the sample was 4.43 .

Parenting Stress. Parents responded to the statement, "I feel overwhelmed by the responsibility of being a parent." Answers were coded 1 if parents responded with "Agree" or "Strongly Agree" and a 0 otherwise. 18\% of parents reported being overwhelmed by parenting responsibilities.

Hopeful about Future. Parents were asked how hopeful they were about the future, and their responses are coded as follows: 0 if "Not at all hopeful", 1 if "A little bit hopeful, 2 if "Mostly hopeful", and 3 if "Very hopeful." The hopeful variable is thus a scale from 0 to 3 . The average score on this scale was 1.99 indicating a relatively high degree of hopefulness about the future.

Regular Reading with Child. This is a dummy variable, coded 1 if the parent reports currently reading with the child 5 or more days per week using either a physical book, phone, or tablet, and a 0 otherwise. $28 \%$ of the participants in the sample engaged in regular reading.

Positive Interactions. This is a scale created from two survey items, namely time spent "hugging or cuddling" and time spent "playing a game or doing something just for fun." Participants were asked whether they did less than usual, the same, or more than the usual amount of these activities relative to before the pandemic. For each of the two variables, we assigned a value of -1 if they did less of the activity, 0 for the same amount, and 1 for more of that activity. The sum of these values across the two variables therefore produces a scale ranging from -2 to 2 , and measures whether the parent engaged in relatively more or fewer of these "positive interactions" during the time they were interviewed during the pandemic. The average 
score on this scale was 1.29 , suggesting that on average there were relatively more positive interactions than usual during the pandemic period.

Child Enjoys Time with Caregiver. Participants were asked how much their child enjoys time with the parent or other caregiver at the time of the survey relative to before the pandemic. We assigned a value of -1 if they said less than usual, 0 for the same amount, and 1 for more than usual, thus providing a variable that ranges from -1 to 1 . The average score was 0.54 , indicating more increased enjoyment than reduced enjoyment during the pandemic.

Parental Yelling or Losing Temper. Participants were asked how often they found themselves yelling at or losing their temper with their child at the time of the survey. We recode responses to this measure to a dichotomous variable equal to 1 if they said "Often" or "All the time", and 0 otherwise (never or sometimes). Nine percent of participants in the sample yelled often or all the time.

Children's Behavioral Non-Compliance. This is a scale comprised of two variables: how much the child "cooperates" and how much the child "argues or is disobedient." Participants were asked to think about a change in their child's behavior since the start of the pandemic and whether their child displayed these behaviors less than usual, the same, or more than usual. For each of the two variables, we assigned a value of -1 if they displayed less of the behavior, 0 for the same amount, and 1 for more of that behavior. In order to treat "cooperating" inversely, we multiplied this by negative 1 (so that 1 indicates less cooperation) and added this with "argues or is disobedient" variable to produce a behavior scale ranging from -2 to 2 . This measures whether the child is engaged in more or fewer of these "noncompliant" interactions during June. The average score on this scale was 0.18 , indicating on average no change in the child's behavioral compliance. 
Covariates. We employ demographic variables as controls throughout our analysis: caregiver sex, race, and education. $92 \%$ of the caregivers in our sample were female, and $39 \%$ had some education beyond high school (coded 1 if the parent report "some college or higher," zero otherwise). For race, we include three dummy variables (black, Hispanic, and a dummy for missing data) and the comparison group is white parents. The criteria for selecting control variables include that they be exogenous to the predictor variables but theoretically plausibly correlated with the predictor and outcome measures.

\section{Missing Data}

Each survey question included an option for "I don't know" and one for "Prefer not to answer." We count either of these responses from a participant as missing data. The majority of missing data values were "Prefer not to answer". In order to focus our empirical analysis on the same group of individuals for all regressions, we dropped participants who had a missing value for any of the nine outcome variables. This reduces the total sample size from 572 to 474 .

There were also some missing values for independent variables. In order to preserve sample size for these variables we entered an arbitrary value (-1) where the data was missing and created a dummy indicator for whether that independent variable had a missing value. Every regression presented here thus includes the missing value dummy for each independent variable that had any missing data, though we do not present these coefficients in the tables.

\section{Analytic Plan}

We use ordinary least squares (OLS) regressions to examine how pandemic induced experiences are associated with parent mental health, parent-child interaction outcomes, and children's behavior. For each of the nine outcome variables, we estimate four regressions: one with the three job and income loss dummies (the omitted group being those with neither job nor 
income loss), a second with struggling to make ends meet measure, a third with COVID exposure, and a fourth with the measure of increased child care time.

\section{Results}

Correlations among all study variables are presented in Table S1. Frequencies and descriptive statistics are presented in Table 1. The results from the regressions are shown in Tables 2 through 10. All analyses presented in Tables 1-10 are conducted on the analytic sample of 474 parents. Table 2 shows that parents who lost both their job and income are significantly more likely to report depressive symptoms relative to the comparison group. This effect is very large - more than $40 \%$ of a standard deviation. In contrast the effect of job loss with no loss of household income was not statistically significant (at $\mathrm{p}<.05)$ nor was it substantively important.

Table 3 shows that the group who experienced both job and income loss also experienced an increase in life stress (an effect size of $46 \%$ of a standard deviation). Parents who experience household income losses alone or who struggle to make ends meet also experienced an increase in life stress of about one third of a standard deviation each. Parents who spend more time on childcare during the pandemic also report modestly higher levels of life stress (an effect size of $19 \%$ of a standard deviation). Parents' exposure to COVID is correlated with an increase in life stress with an effect size of $17 \%$ but that is not statistically significant (at $p<.05$ ).

Table 4 shows that none of our measures of COVID experiences is significantly related to parenting stress. The results in Table 5 however illustrate the adverse effects of economic hardship on feeling hopeful: Those with both job and income loss report feeling less hopeful about the future (an effect size of $24 \%$ of a standard deviation) as do those who struggle to make ends meet (a very substantial effect size of $58 \%$ of a standard deviation). We also see that parents' exposure to COVID itself is correlated with a decrease in feeling hopeful with an effect 
size of $17 \%$ but that is not statistically significant (at $\mathrm{p}<.05)$.

Turning now to our measures of parent-child interaction, Table 6 shows that parents who have job and income loss are more likely to be regular readers with their children. The effect here represents an increase of 11 percentage points (the sample average is 28 percent). Thus, this is a substantively important effect though it is only significant at $p<.10$. Table 7 shows that parents who lose just their jobs but not household income are more likely to engage in positive interactions with their child. Although this effect is only significant at $\mathrm{p}<.10$, the effect size is about one third of a standard deviation. Parents who report spending more childcare time during the pandemic also report much higher levels of positive interaction - with an effect size of about $50 \%$ of a standard deviation. In contrast parents who have experienced COVID exposure report much lower levels of positive interactions with their children (with an effect size of 43 percent).

Table 8 looks at negative interactions between parents and children. Parents who experience a job and income loss, as well as those with just income loss, are more likely to lose their temper or yell at their child. Given that the sample mean on this outcome is only nine percent, these effects are quite large at $11 \%$ and eight percent respectively. In contrast though the sign of the coefficient on "job loss only" is positive, the effect is very small (1.5\%) and not statistically significant.

Finally, we turn to our measures of parents' reports of their child's emotional adjustment. Table 9 shows that parents who lose just their job (but do not experience a household income decline) are more likely to say their child enjoys time with them. Although this effect is significant only at $\mathrm{p}<.10$ its effect size is about one third of a standard deviation. Parents who report an increase in childcare time also report a significant increase in the child enjoying time with them, with an effect size of $21 \%$. In contrast, parents who struggle to make ends meet are 
far less likely to report that the child enjoys spending time with them (an effect size of about one third of a standard deviation). Table 10 examines parental reports of children's behavioral noncompliance. Parents with COVID exposure are more likely to report an increase in their child's noncompliant behavior. The effect size is $44 \%$ of a standard deviation.

\section{Discussion}

While we hope the pandemic will come to a close soon, the results from our analysis can help us understand the broader impact of economic and social shocks on family dynamics. Our research provides new insights that can help policy makers and practitioners support low income families who are struggling with these shocks now and in the future. First, our data show high levels of job loss, income declines, and perceived inability to make ends meet. Overall $45 \%$ of our sample experienced either a job loss or a substantial household income loss due to the pandemic. But it is the combination of job and income loss that seems to create stress and hurt child development. While this pandemic will one day come to a close, job loss will be with us forever and these results suggest that government efforts to stem the income loss associated with job loss could greatly contribute to family stability and child success. Moreover, the economic stresses of the COVID-19 crisis have worsened mothers' mental health and stress, diminished their sense of hope for the future, and substantially increased the amount that parents yell and lose their temper with their young children. This calls for interventions aimed at supporting mothers' mental health (see e.g. McFarlane et al., 2017).

Nonetheless, adverse effects are never apparent among the families in our sample who report a pandemic-induced job loss but not a concomitant household income loss. We do not know how these families avoided a household income loss but there are several possibilities. Unemployment compensation plus federal stimulus money to families may have prevented 
income loss. Other household members may have experienced an income gain from working more hours, for example as essential workers. Moreover, we find that this group of families who lost their jobs (and were unemployed at the time of the survey) but maintained their income sometimes reports better family interactions - they report more positive interactions with their child and they report that their child more often enjoys the time with them. This highlights the importance of time to parenting. For parents having both income and time to spend with their children is important. If they can have more time with no loss income, their interactions will improve. This may suggest generous paid family leave is a promising way to improve child outcomes.

Although parents experiencing job and income losses and those reporting an inability to make ends meet are much more likely to report diminished mental health, they are no more likely to report being overwhelmed by their responsibilities as parents nor do these experiences detract from the quality of the parent-child interactions. An exception here is the degree to which parents report yelling at their child, which is strongly correlated with job and income loss, income loss alone, and struggling to make ends meet (but, again, not job loss alone). Parents' reports of their own economic stress are also not correlated with their reports of their children's behavioral adjustment. This suggests that many parents in our sample were able to shield their children to some extent from their own personal stress arising from household economic struggles. It will be important for future research to understand how long parents are able to remain resilient in this way, and the factors that shape the ability to do so. It is certainly possible that if economic hardship wears on its ill effects could spill over into parent-child interactions.

Parents' exposure to COVID-19 itself is associated with substantially lower levels of positive parent-child interaction and substantially higher levels of parents' reports of children's 
behavioral non-compliance. There is also a strong suggestion in the data that exposure to COVID-19 is associated with higher levels of parental life stress and a diminished sense of hope. In fact, exposure to COVID was the only one of our predictor variables that was correlated with children's behavioral adjustment. We do not know of other studies that have established this finding but it is certainly worrisome to the extent that cases continue to rise in various locations around the U.S.

Finally, we identify one dimension of low income families' pandemic experience that seems consistently positive - an increase in the amount of time that parents are spending with their pre-school age children in the wake of school closings. Seventy-five percent of the parents in our study reported that they were spending much more pandemic-induced time caring for their young children. Although this experience was modestly stressful on average for parents in our study, it was also a significant positive predictor of the parents' perception that the child enjoyed the time with the parent and the parents' report of more positive interactions with the child. These results are consistent with prior work showing that the time parents spend with their children is characterized by very high levels of positive affect and meaning (Kalil et al., 2020).

In sum, these results make clear that the complete story of economic and social shocks on family dynamics and children's adjustment remains to be told. COVID-19 will eventually end, but the economic and social forces shaping family life will remain with us and may take new shapes in the future. Understanding these phenomena, and crafting the appropriate policy response to mitigating these shocks on parents and children, should be a top priority for scholars and policy makers alike.

\section{References}


Attanasio, O., Blundell, R., \& Conti, G. (in press). (2020). Inequality in socio-emotional skills: a cross-cohort comparison. Journal of Public Economics. https://doi.org/10.1016/j.jpubeco.2020.104171.

Baxter, J., Budinski, M., Carroll, M., \& Hand, K. Australian Institute of Family Studies (2020). Families in Australia survey: Life during COVID-19 - Report no. 5: What we did during lockdown. https://aifs.gov.au/publications/what-we-did

Calarco, J., Meanwell, E., Anderson, E., \& Knopf, A. (2020). Let's not pretend it's fun: a mixedmethods analysis of increased time with children and mothers' well-being during the COVID-19 pandemic

https://static1.squarespace.com/static/55b27527e4b0029a63553153/t/5f74f4e32ac66957 16baba11/1601500388592/Lets + Not+Pretend + Its + Fun_PPS_2020.09.30_socarxiv.pdf

Conger, R. D., Wallace, L. E., Sun, Y., Simons, R. L., McLoyd, V. C., \& Brody, G. H. (2002). Economic pressure in African American families: A replication and extension of the family stress model. Developmental Psychology, 38(2), 179-193. https://doi.org/10.1037/0012-1649.38.2.179

Cunha, F., Heckman, J., Lochner, L., \& Masterov, D. (2006). Interpreting the evidence on life cycle skill formation. In E. Hanushek \& F. Welch (Eds.), Handbook of the economics of education (Vol. 1, pp. 697-812). North Holland. https://doi.org/10.1016/S1574$\underline{0692(06) 01012-9}$

Del Boca, D., Flinn, C., \& Wiswall, M. (2014). Household choices and child development. The Review of Economic Studies, 81(1), 137-185. https://doi.org/10.1093/restud/rdt026

Doepke, M., \& Zilibotti, F. (2019). Love, money, and parenting: How economics explains the way we raise our kids. Princeton University Press. 
Duncan, G., \& Magnuson, K. (2011). The nature and impact of early achievement skills, attention skills, and behavior problems. In G. Duncan \& R. Murnane (Eds.), Whither opportunity: Rising inequality, schools, and children's life chances (pp. 47-69). Russell Sage. https://doi.org/10.1080/15582159.2013.759847

Duncan, G. J., Ziol-Guest, K. M., \& Kalil, A. (2010). Early-childhood poverty and adult attainment, behavior, and health. Child Development, 81(1), 306-325. https://doi.org/10.1111/j.1467-8624.2009.01396.x

Fiorini, M., \& Keane, M. P. (2014). How the allocation of children's time affects cognitive and noncognitive development. Journal of Labor Economics, 32(4), 787-836. https://doi.org/10.1086/677232

Ganong, P., Noel, P., \& Vavra, J. (2020). U.S. unemployment insurance replacement rates during the pandemic (Working Paper No. 2020-62). https://bfi.uchicago.edu/workingpaper/2020-62/

Gassman-Pines, A., Ananat, E. O., \& Fitz-Henley, J. (2020). COVID-19 and parent-child psychological well-being. Pediatrics, e2020007294. https://doi.org/10.1542/peds.2020$\underline{007294}$

Gershoff, E. T., Lansford, J. E., Sexton, H. R., Davis-Kean, P., \& Sameroff, A. J. (2012). Longitudinal links between spanking and children's externalizing behaviors in a national sample of White, Black, Hispanic, and Asian American families. Child Development, 83(3), 838-843. https://doi.org/10.1111/j.1467-8624.2011.01732.x

Hsin, A., \& Felfe, C. (2014). When does time matter? Maternal employment, children's time with parents, and child development. Demography, 51(5), 1867-1894.

https://doi.org/10.1007/s13524-014-0334-5 
Jackson, A. P., Brooks-Gunn, J., Huang, C., \& Glassman, M. (2000). Single mothers in lowwage jobs: Financial strain, parenting, and preschoolers' outcomes. Child Development, 71(5), 1409-1423. https://doi.org/10.1111/1467-8624.00236.

Kalil, A. (2013). Effects of the great recession on child development. The Annals of the American Academy of Political and Social Science, 650(1), 232-250. https://doi.org/10.1177/0002716213500453

Kalil, A., Mayer, S. E., Delgado, W., \& Gennetian, L. A. (2019). The education gradient in maternal enjoyment of time in childcare (Working Paper No. 2020-131). https://bfi.uchicago.edu/wp-content/uploads/2020/09/BFI_WP_2020131.pdf

Kalil, A., \& Ryan, R. (2020). Parenting practices and socioeconomic gaps in childhood outcomes. The Future of Children, 30, 29-54. https://doi.org/10.1353/foc.2020.0004

Kalil, A., Ryan, R., \& Corey, M. (2012). Diverging destinies: Maternal education and the developmental gradient in time with children. Demography, 49(4), 1361-1383. https://doi.org/10.1007/s13524-012-0129-5

Kuhfeld, M., Soland, J., Tarasawa, B., Johnson, A., Ruzek, E., \& Liu, J. (2020). Projecting the potential impacts of COVID-19 school closures on academic achievement (Working Paper No. 20-226). https://doi.org/10.26300/cdrv-yw05

Landry, S. H., Smith, K. E., \& Swank, P. R. (2006). Responsive parenting: Establishing early foundations for social, communication, and independent problem-solving skills. Developmental Psychology, 42(4), 627-642. https://doi.org/10.1037/0012-1649.42.4.627

Linver, M. R., Brooks-Gunn, J., \& Kohen, D. E. (2002). Family processes as pathways from income to young children's development. Developmental Psychology, 38(5), 719-734. https://doi.org/10.1037//0012-1649.38.5.719 
McFarlane, E., Burrell, L., Duggan, A., \& Tandon, D. (2017). Outcomes of a randomized trial of a cognitive behavioral enhancement to address maternal distress in home visited mothers. Maternal and Child Health Journal, 21(3), 475-484. https://doi.org/10.1007/s10995-016$\underline{2125-7}$

Moroni, G., Nicoletti, C., \& Tominey, E. (2019). Child socio-emotional skills: The role of parental inputs (Discussion Paper No. 12432). Human Capital and Economic Opportunity Working Group. http://ftp.iza.org/dp12432.pdf

Pinderhughes, E. E., Dodge, K. A., Bates, J. E., Pettit, G. S., \& Zelli, A. (2000). Discipline responses: Influences of parents' socioeconomic status, ethnicity, beliefs about parenting, stress, and cognitive-emotional processes. Journal of Family Psychology, 14(3), 380-400. https://doi.org/10.1037//0893-3200.14.3.380

Price, J., \& Kalil, A. (2019). The effect of mother-child reading time on children's reading skills: Evidence from natural within-family variation. Child Development, 90(1), e688-e702. http://www.uvic.ca/socialsciences/economics/assets/docs/pastdept4/price_parental_time.pdf

Ryan, R. M., Kalil, A., Ziol-Guest, K. M., \& Padilla, C. (2016). Socioeconomic gaps in parents' discipline strategies from 1988 to 2011. Pediatrics, 138(6), e20160720. https://doi.org/10.1542/peds.2016-0720

Sapolsky, R. M. (2004). Mothering style and methylation. Nature Neuroscience, 7(8), 791-792. https://doi.org/10.1038/nn0804-791

Sevilla, A., \& Smith, S. (2020). Baby steps: The gender division of childcare during the COVID19 pandemic. Oxford Review of Economic Policy, 36, S169-S186. https://doi.org/10.1093/oxrep/graa027 
Shonkoff, J. P., \& Phillips, D. A. (2000). From neurons to neighborhoods: The science of early childhood development. The National Academies Press. https://doi.org/10.17226/9824.

Straus, M. A., \& Stewart, J. H. (1999). Corporal punishment by American parents: National data on prevalence, chronicity, severity, and duration, in relation to child and family characteristics. Clinical Child and Family Psychology Review, 2(2), 55-70.

https://doi.org/10.1023/A:1021891529770 
Table 1

Descriptive Statistics of COVID-19 Survey Study Variables

\begin{tabular}{lcccc}
\hline Variable & Mean & Std. Dev. & Min & Max \\
\hline Sample Characteristics & & & & \\
\hline Female Caregiver & 0.92 & 0.27 & 0.00 & 1.00 \\
At least Some College & 0.39 & 0.49 & 0.00 & 1.00 \\
White & 0.14 & 0.35 & 0.00 & 1.00 \\
Black & 0.24 & 0.43 & 0.00 & 1.00 \\
Hispanic & 0.33 & 0.47 & 0.00 & 1.00 \\
Unknown Race & 0.29 & 0.46 & 0.00 & 1.00 \\
& & & & \\
Predictors & & & & \\
Job and Income Loss & 0.15 & 0.36 & 0.00 & 1.00 \\
Only Job Loss & 0.09 & 0.28 & 0.00 & 1.00 \\
Only Income Loss & 0.21 & 0.41 & 0.00 & 1.00 \\
Struggle to Make Ends Meet & 0.20 & 0.40 & 0.00 & 1.00 \\
$\quad$ Sick with COVID symptoms & 0.10 & 0.30 & 0.00 & 1.00 \\
More Time Childrearing & 0.74 & 0.44 & 0.00 & 1.00 \\
& & & & \\
Outcomes & & & 0.00 & 6.00 \\
$\quad$ Depressive Symptoms Scale & 0.99 & 1.28 & 0.00 & 10.00 \\
Life Stress & 4.43 & 2.88 & 0.00 & 1.00 \\
$\quad$ Parenting Stress & 0.18 & 0.39 & 0.00 & 3.00 \\
Hopeful for Future & 1.99 & 0.93 & 0.00 & 1.00 \\
Regular Reading & 0.28 & 0.45 & -2.00 & 2.00 \\
Positive Interaction Scale & 1.29 & 0.97 & 0.00 & 1.00 \\
Yelling or Losing Temper & 0.09 & 0.28 & -1.00 & 1.00 \\
Child Enjoys Time & 0.54 & 0.56 & -2.00 & 2.00 \\
Child Non-compliance Scale & 0.18 & 1.08 & & \\
\hline N & 474 & &
\end{tabular}

Note. The mean for dummy variables represents the proportion with a value of 1. 
Table 2

OLS Regression Results, COVID-19 Experiences as Predictors of Depressive Symptoms

\begin{tabular}{ccccc}
\hline Variable & $(1)$ & $(2)$ & $(3)$ & $(4)$ \\
& Depressive & Depressive & Depressive & Depressive \\
& Symptoms & Symptoms & Symptoms & Symptoms \\
\hline Job and Income Loss & $.545^{* * *}$ & & & \\
& $(.177)$ & & &
\end{tabular}

Only Job Loss $\quad-.154$

$(.223)$

Only Income Loss $\quad .076$

$(.156)$

Struggle to Meet Ends $\quad .216$

$(.152)$

Sick with COVID

$-.134$

$(.201)$

More Childcare Time

.055

$(.135)$

$\begin{array}{lllll}\text { Observations } & 474 & 474 & 474 & 474\end{array}$

Note. Standard errors are in parentheses. All regressions control for parent/caregiver's gender, race, and education level. All regressions also control for a missing value dummy for the independent variable(s) in the regression.

$* * * p<.01, * * p<.05, * p<.1$

Table 3

OLS Regression Results, COVID-19 Experiences as Predictors of Life Stress

\begin{tabular}{ccccc}
\hline Variable & $(1)$ & $(2)$ & $(3)$ & $(4)$ \\
& Stress & Stress & Stress & Stress \\
\hline Job and Income Loss & $1.317^{* * *}$ & & &
\end{tabular}

Only Job Loss

$-.146$

(.493)

Only Income Loss

$.95 * * *$

(.344)

Struggle to Meet Ends

Sick with COVID

More Childcare Time

(.3)

\begin{tabular}{lllll}
\hline Observations & 474 & 474 & 474 & 474 \\
\hline
\end{tabular}

Note. Standard errors are in parentheses. All regressions control for parent/caregiver's gender, race, and education level. All regressions also control for a missing value dummy for the independent variable(s) in the regression.

$* * * p<.01, * * p<.05, * p<.1$ 
Table 4

OLS Regression Results, COVID-19 Experiences as Predictors of Parenting Stress

\begin{tabular}{ccccc}
\hline Variable & $(1)$ & $(2)$ & $(3)$ & $(4)$ \\
& Overwhelmed & Overwhelmed & Overwhelmed & Overwhelmed \\
\hline Job and Income Loss & .003 & &
\end{tabular}

Only Job Loss $\quad-.013$

Only Income Loss $\quad-.024$

Struggle to Meet Ends $\quad .043$

(.046)

Sick with COVID

.03

$(.061)$

More Childcare Time $\quad-.003$

\begin{tabular}{llllc} 
& & & $(.041)$ \\
\hline Observations & 474 & 474 & 474 & 474
\end{tabular}

Note. Standard errors are in parentheses. All regressions control for parent/caregiver's gender, race, and education level. All regressions also control for a missing value dummy for the independent variable(s) in the regression.

$* * * p<.01, * * p<.05, * p<.1$

Table 5

OLS Regression Results, COVID-19 Experiences as Predictors of Being Hopeful

\begin{tabular}{clccc}
\hline & $(1)$ & $(2)$ & $(3)$ & $(4)$ \\
Variable & Hopeful & Hopeful & Hopeful & Hopeful \\
\hline Job and Income Loss & $-.225^{*}$ & & & \\
& $(.128)$ & & &
\end{tabular}

Only Job Loss $\quad-.085$

$(.161)$

Only Income Loss $\quad .005$

$(.112)$

Struggle to Meet Ends

$-.45^{* * *}$

(.107)

Sick with COVID

$-.161$

$(.144)$

More Childcare Time $\quad-.062$

$(.096)$

\begin{tabular}{ccccc}
\hline Observations & 474 & 474 & 474 & 474 \\
\hline Note. Standard errors are in parentheses. All regressions control for parent/caregiver's
\end{tabular}

Note. Standard errors are in parentheses. All regressions control for parent/caregiver's gender, race, and education level. All regressions also control for a missing value dummy for the independent variable(s) in the regression.

$* * * p<.01, * * p<.05, * p<.1$ 
Table 6

OLS Regression Results, COVID-19 Experiences as Predictors of Regular Reading

\begin{tabular}{ccccc}
\hline Variable & $(1)$ & $(2)$ & $(3)$ & $(4)$ \\
& Reading & Reading & Reading & Reading \\
\hline Job and Income Loss & $.114^{*}$ & & & \\
& $(.061)$ & & &
\end{tabular}

Only Job Loss $\quad-.01$

Only Income Loss $\quad-.065$

$(.054)$

Struggle to Meet Ends $\quad-.013$

$(.052)$

Sick with COVID -.063

$(.069)$

More Childcare Time $\quad .076$

(.046)

$\begin{array}{ccccc}\text { Observations } & 474 & 474 & 474 & 474 \\ \text { Note. Standard errors are in parentheses. All regressions control for parent/caregiver' }\end{array}$

gender, race, and education level. All regressions also control for a missing value

dummy for the independent variable(s) in the regression.

$* * * p<.01, * * p<.05, * p<.1$

Table 7

OLS Regression Results, COVID-19 Experiences as Predictors of Positive Interactions

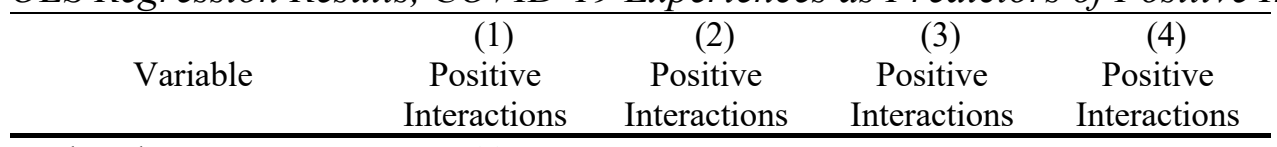

Job and Income Loss $\quad .22$

Only Job Loss

$.325 *$

(.168)

Only Income Loss

.026

(.117)

Struggle to Meet Ends

(.114)

Sick with COVID

$-.419^{* * *}$

(.15)

More Childcare Time

$476^{* * *}$

(.099)

Observations

474

474

474

474

Note. Standard errors are in parentheses. All regressions control for parent/caregiver's gender, race, and education level. All regressions also control for a missing value dummy for the independent variable(s) in the regression.

$* * * p<.01, * * p<.05, * p<.1$ 
Table 8

OLS Regression Results, COVID-19 Experiences as Predictors of Yelling/Losing Temper

\begin{tabular}{ccccc}
\hline Variable & $(1)$ & $(2)$ & $(3)$ & $(4)$ \\
& Yelling & Yelling & Yelling & Yelling \\
\hline Job and Income Loss & $.107^{* * *}$ & & & \\
& $(.039)$ & & &
\end{tabular}

Only Job Loss $\quad .015$

Only Income Loss $\quad .077^{* *}$

Struggle to Meet Ends $\quad .026$

$(.034)$

Sick with COVID

$\begin{array}{ll}\text { More Childcare Time } & .028\end{array}$

Observations (.03)

\begin{tabular}{ccccc} 
Observations & 474 & 474 & 474 & 474 \\
\hline Note. Standard errors are in parentheses. All regressions control for parent/caregiver's
\end{tabular}

gender, race, and education level. All regressions also control for a missing value

dummy for the independent variable(s) in the regression.

$* * * p<.01, * * p<.05, * p<.1$

Table 9

OLS Regression Results, COVID-19 Experiences as Predictors of Child Enjoying Time

\begin{tabular}{ccccc}
\hline Variable & $(1)$ & $(2)$ & $(3)$ & $(4)$ \\
& Enjoys Time & Enjoys Time & Enjoys Time & Enjoys Time \\
\hline Job and Income Loss & .086 & & &
\end{tabular}

Only Job Loss $\quad .19^{*}$

Only Income Loss $\quad-.06$

(.068)

Struggle to Meet Ends

$-.189 * * *$

(.066)

Sick with COVID

$-.006$

(.088)

More Childcare Time

$.12 * *$

Observations 474
Note. Standard errors are in parentheses. All regressions control for parent/caregiver's
gender, race, and education level. All regressions also control for a missing value
dummy for the independent variable(s) in the regression.
$* * * p<.01, * * p<.05, * p<.1$


Table 10

OLS Regression Results, COVID-19 Experiences as Predictors of Child Non-Compliance

\begin{tabular}{ccccc}
\hline Variable & $(1)$ & $(2)$ & $(3)$ & $(4)$ \\
& Non-Compliant & Non-Compliant & Non-Compliant & Non-Compliant \\
\hline Job and Income Loss & .056 & &
\end{tabular}

Only Job Loss $\quad .067$

Only Income Loss $\quad-.027$

$(.131)$

Struggle to Meet Ends

.113

$(.127)$

Sick with COVID

$.467 * * *$

$(.167)$

More Childcare Time

.005

(.113)

Observations

474

474

474

474

Note. Standard errors are in parentheses. All regressions control for parent/caregiver's gender, race, and education level. All regressions also control for a missing value dummy for the independent variable(s) in the regression.

$* * * p<.01, * * p<.05, * p<.1$ 